\title{
Double Inverted Mesiodentes: Report of an Unusual Case
}

\author{
Ebru Canoglua \\ Nuray $\mathrm{Er}^{\mathrm{b}}$ \\ Zafer C. Cehrelic
}

\section{ABSTRACT}

This report presents an extremely rare occurrence of two inverted mesiodentes in a child patient. Extraction of both mesiodentes was indicated, owing to the axial rotation of the permanent central incisors caused by these impacted supernumerary teeth. Radiographic evidence of complete healing was observed 24 months following surgical removal of the inverted mesiodentes. (Eur J Dent 2009;3:219-223)

Key words: Mesiodens; Inversion; Supernumerary tooth.

\section{INTRODUCTION}

Supernumerary teeth are a relatively frequent disorder of odontogenesis characterized by an excess number of teeth, with mesiodens being the most frequent. ${ }^{1}$ The term of mesiodens is used to refer to an unerupted supernumerary tooth in the midline of maxilla, between the central incisors. ${ }^{2,3}$ The incidence of mesiodens among

a Research Assistant, Department of Pediatric Dentistry, Faculty of Dentistry, Hacettepe University, Ankara, Turkey.

b Professor, Department of Oral Surgery, Faculty of Dentistry, Hacettepe University, Ankara, Turkey.

Associate Professor, Department of Pediatric Dentistry, Faculty of Dentistry, Hacettepe University, Ankara, Turkey.

- Corresponding author: Zafer C. Cehreli, DDS, PhD Department of Pediatric Dentistry

Faculty of Dentistry, Hacettepe University

Ankara,Turkey.

Fax: +903123243190

E-mail: zcehreliahacettepe.edu.tr zcehreliagmail.com
Caucasians is $0.15-3 \%$ for permanent teeth, ${ }^{4,5}$ and is found two times more frequently in males, compared to females. ${ }^{4-6} \mathrm{~A}$ mesiodens can manifest bilaterally, ${ }^{4-6}$ or in an inverted (upward) position. ${ }^{4,5}$ The frequency of inverted mesiodens constitutes to approximately $9-67 \%$ of all reported cases. ${ }^{7-11}$ To date, a total of 278 single inverted mesiodentes have been reported (Table 1).

The mesiodens may present a rudimentary morphology with a cone-shaped crown, generally smaller in size than the adjacent normal teeth. It may also be found to mimic a natural tooth shape. The root is often totally formed, and may be curved or globular. ${ }^{12}$ Mesiodens is frequently associated with several craniofacial disturbances, including cleft lip and palate ${ }^{13}$ and cleidocranial dysostosis; ${ }^{14}$ and to a lesser extent with Gardner's syndrome or chondorectodermal dysplasia. ${ }^{15}$

Only $25 \%$ of all mesiodentes spontaneously erupt into the oral cavity. ${ }^{6}$ In general, they remain impacted and asymptomatic; and are 
commonly discovered during routine radiographic examination. ${ }^{16}$ The most common complications of mesiodentes are the delay or prevention of eruption (26-52\%) and displacement/rotation (28$60 \%$ ) of maxillary permanent incisors. Relatively less common complications include crowding, diastema, dilaceration of permanent teeth, cyst formation and eruption into the nasal cavity. ${ }^{6}$

This case reports presents radiographic features of a unique occurrence of two impacted, inverted mesiodentes in a child patient; and the 24-month radiographic and clinical follow-up after surgical removal.

\section{CASE REPORT}

An 8-year-old boy was referred to the Department of Pediatric Dentistry with a chief complaint of crowding in the maxillary anterior region. Being born to non-consanguineous parents, the patient's health status was excellent. The intraoral examination confirmed the patient's chief complaint (Figure 1). Panoramic radiograph revealed the presence of two supernumerary teeth, located between the roots of the permanent central incisors (Figure 2). Occlusal and periapical radiographs of the region showed that these two teeth were inverted mesiodentes (Figure 3). Apparently, the roots of the permanent central incisors had migrated distally, owing to the presence of the supernumerary teeth. The lateral cephalogram showed that the mesiodentes were located buccally to the apices of the central incisors (Figure 4).

The treatment plan consisted of surgical removal the inverted mesiodentes. The teeth were removed under general anaesthesia without any complication (Figure 5). Following removal of sutures one week later, the patient was scheduled for bimonthly recalls. At the second-month recall, new bone formation was detected radiographically within the extraction sites (Figure 6).

Radiographic evidence of complete healing was observed 24 months later. The extraction cavities were completely filled with bone (Figure 6) and the permanent central incisors responded favorably to thermal and electrical pulp tests. Removal of the inverted mesiodentes had slightly aided to self-correction of the axial rotations of the central incisors. The patient was referred to the Orthodontics department for the management of crowding.

\section{DISCUSSION}

Although mesiodentes are often located palatally, ${ }^{2}$ the present case demonstrates the possibility of their occurrence in a more vestibular

Table 1. Previous publications reporting the occurrence of inverted mesiodens with respect to number and location.

\begin{tabular}{lc}
\hline Investigators (year) & Number of mesiodens \\
\hline Kanterman (1956) & 1 \\
Yarnis (1966) & 1 \\
Papgiannis et al. (1970) & 1 \\
Soni et al. (1972) & 1 \\
Sykaras (1975) & 1 \\
Gallant (1980) & 1 \\
Atasu et al. (1999) & 1 \\
Nikhil et al. (1999) & 1 \\
Roychoudhury et al. (2000) & 20 \\
Srivastava et al. (2001) & 1 \\
Kim et al. (2003) & 26 \\
Asaumi et al. (2004) & 172 \\
Ersin et al. (2004) & 3 \\
Tyrologou et al. (2005) & 48 \\
Dinkar et al. (2007) & 2 \\
\hline
\end{tabular}


location. In addition to routine ortopantomography or periapical/occlusal radiographs which can rapidly solve the initial diagnostic phase of mesiodentes, further techniques may be required

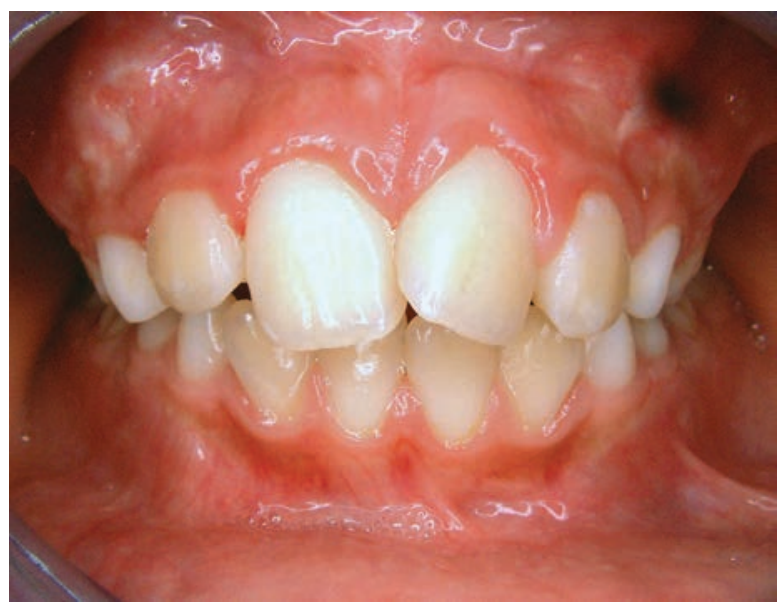

Figure 1. Intraoral view of the patient, demonstrating crowding in the anterior region. Note the extent of deviation in the vertical axis of maxillary central incisors.

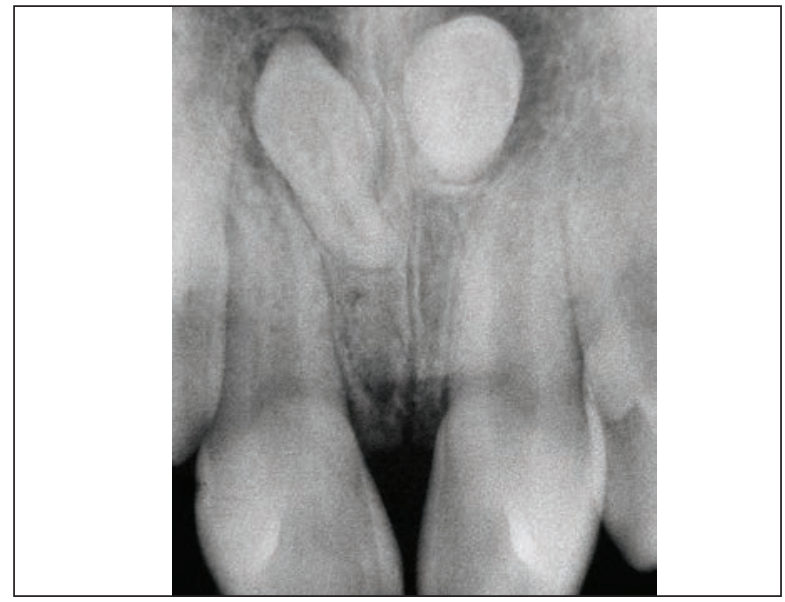

Figure 3. Periapical radiograph of the inverted mesiodentes.

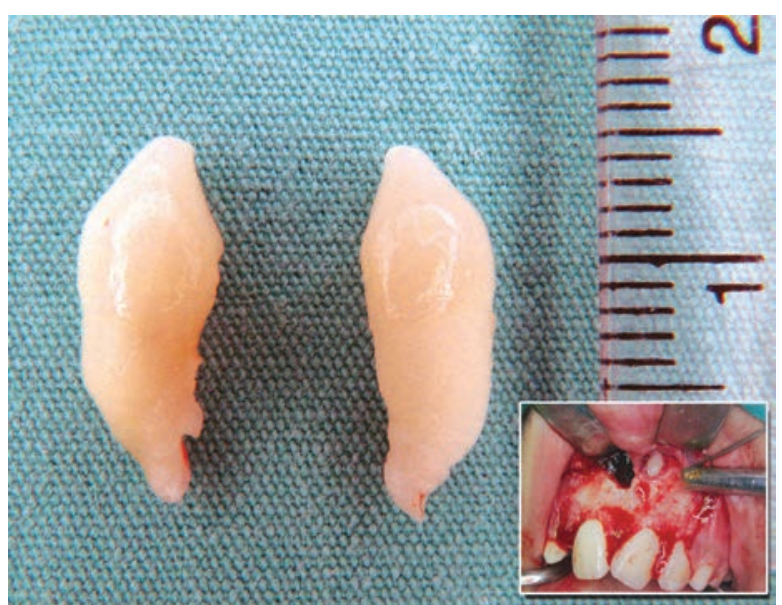

Figure 5. View of the mesiodentes after surgical removal. Inner picture: Operative view of the patient, demonstrating extraction site of the right mesiodens and removal of cortical bone over the crown of the left mesiodens. to better define their position in relation to the adjacent teeth and anatomic structures. In the present case, the exact route (i.e., buccal/palatal) for surgical removal of the inverted mesiodentes

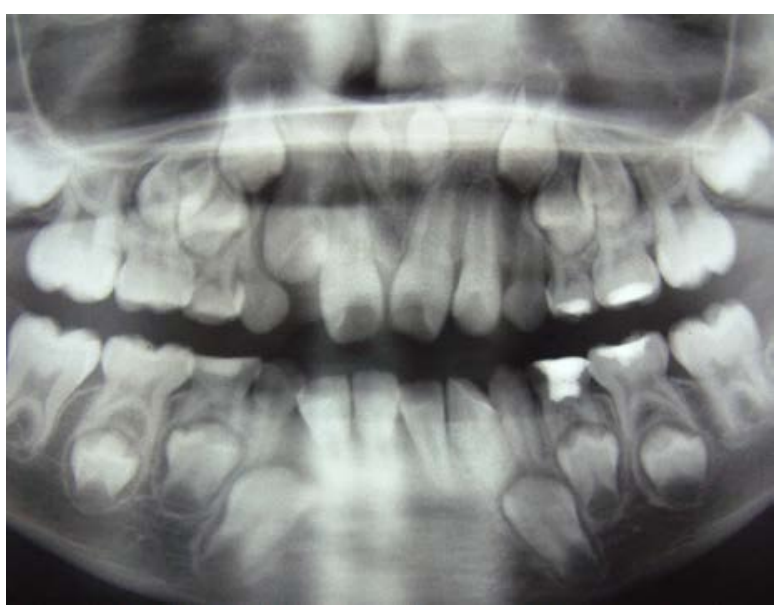

Figure 2. Panoramic radiograph, revealing double inverted mesiodentes.

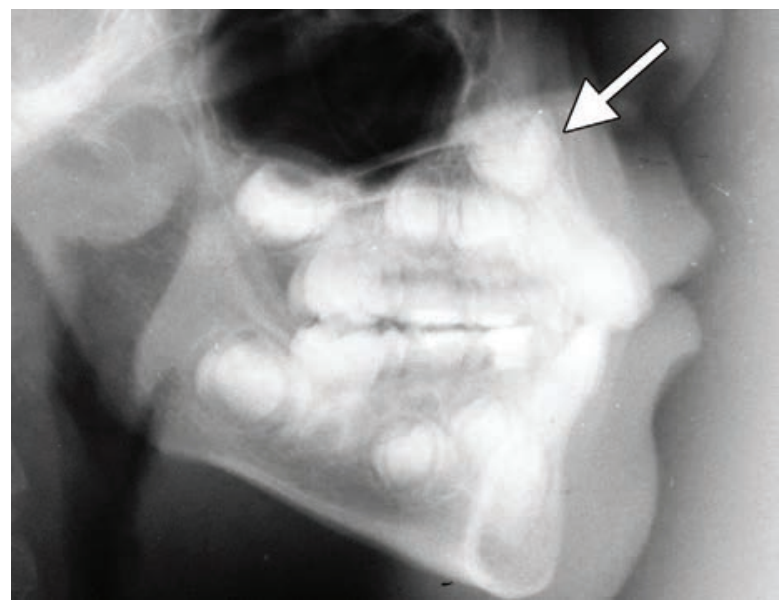

Figure 4. Lateral cephalogram of the patient, showing the position of mesiodentes with respect to the roots of central incisors.

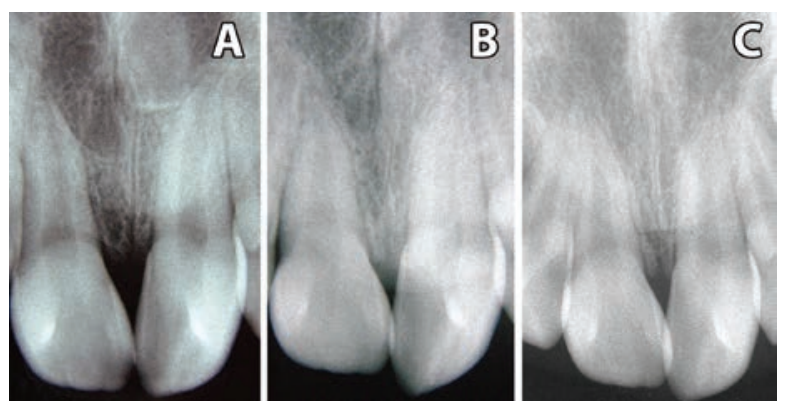

Figure 6. Radiographic view of the extraction site at postoperative 2 months (left) and one year (right). Note the extent of osseous healing. 
could only be determined after obtaining a lateral cephalogram. Undoubtedly, greater detail concerning their location could be obtained through computerized axial tomography (CAT),17 which also can help evaluate their relationship with the adjacent tooth structures. In this regard, periapical and occlusal radiographs were used in conjunction with the lateral cephalogram, since CAT was not available in our centre.

Extraction is not the only treatment choice for impacted mesiodentes. If the mesiodens remains in place without symptoms and does not adversely affect the adjacent teeth, it may be left in place and observed periodically. ${ }^{16}$ In the present case, surgical removal of the mesiodentes was judged necessary, since these teeth had caused axial rotation of the permanent central incisors.

There are no precise indications concerning the ideal time for surgical removal of impacted mesiodens. According to Atwan, ${ }^{18}$ a mesiodens can be best removed when the permanent central incisors start to erupt, but this may not be always possible. Contrary, Primosh ${ }^{19}$ discourages early extraction of mesiodentes due to the risk of iatrogenic damage to the developing adjacent permanent teeth. In the present case, the timing for surgical removal of the inverted mesiodentes was judged to be suitable, since both maxillary central incisors had totally erupted, showing complete root formation and advanced apical closure.

The case presented herein was considered to be extremely rare, since inversion of two mesiodentes in a single patient has only been reported once ${ }^{20}$ (Table 1). The clinical significance of the inversion is questionable, since both mesiodentes remained intact; i.e., did not erupt ectopically. However, the occurrence of two mesiodentes was definitely regarded as a contributory factor to the crowding in the anterior maxillary region, as evidenced by the deviation in the vertical axis of both central incisor teeth. Fortunately, the post-surgical phase was uneventful, and did not affect commencement of fixed orthodontic therapy after a relatively short follow-up period.

\section{REFERENCES}

1. Gallas MM, Garcia A. Retention of permanent incisors by mesiodens: a family affair. Br Dent J 2000;188:63-64.
2. Seddon RP, Johnstone SC, Smith PB. Mesiodentes in twins: a case report and a review of the literature. Int $J$ Paediatr Dent 1997;7:177-184.

3. Segura JJ, Jimenez-Rubio A. Concomitant hypohyperdontia: simultaneous occurrence of a mesiodens and agenesis of a maxillary lateral incisor. Oral Surg Oral Med Oral Pathol Oral Radiol Endod 1998;86:473-475.

4. Sedano HO, Gorlin RJ. Familial occurrence of mesiodens. Oral Surg Oral Med Oral Pathol 1969;27:360-361.

5. Shafer M, Hine M, Levy B. Developmental disturbances of oral and paraoral structures. Textbook of Oral Pathology: Philedelphia: Saunders; 47-49, 1983.

6. Hattab FN, Yassin OM, Rawashdeh MA. Supernumerary teeth: report of three cases and review of the literature. ASDC J Dent Child 1994;61:382-393.

7. Asaumi Jl, Shibata Y, Yanagi Y, Hisatomi M, Matsuzaki $H$, Konouchi $\mathrm{H}$, et al. Radiographic examination of mesiodens and their associated complications. Dentomaxillofac Radiol 2004;33:125-127

8. Ersin NK, Candan U, Alpoz AR, Akay C. Mesiodens in primary, mixed and permanent dentitions: a clinical and radiographic study. J Clin Pediatr Dent 2004;28:295-298.

9. Kim SG, Lee SH. Mesiodens: a clinical and radiographic study. J Dent Child (Chic) 2003;70:58-60.

10. Roychoudhury A, Gupta Y, Parkash H. Mesiodens: a retrospective study of fifty teeth. J Indian Soc Pedod Prev Dent 2000;18:144-146.

11. Tyrologou S, Koch G, Kurol J. Location, complications and treatment of mesiodentes--a retrospective study in children. Swed Dent J 2005;29:1-9.

12. Giancotti A, Grazzini F, De Dominicis F, Romanini G, Arcuri C. Multidisciplinary evaluation and clinical management of mesiodens. J Clin Pediatr Dent 2002;26:233-237.

13. Böhn A. Dental anomalies in harelip and cleft palate. Acta Odontol Scand 1963;21:1-14

14. Richardson A, Deussen FF. Facial and dental anomalies in cleidocranial dysplasia: a study of 17 cases. Int J Paediatr Dent 1994;4:225-231.

15. Gorlin R, Hennekam R. Syndromes of the head and neck: Oxford University Pres; 2001.

16. Rajab LD, Hamdan MA. Supernumerary teeth: review of the literature and a survey of 152 cases. Int J Paediatr Dent 2002;12:244-254.

17. Bodner L, Sarnat H, Bar-Ziv J, Kaffe I. Computed tomography in the management of impacted teeth in children. ASDC J Dent Child 1994;61:370-377.

18. Atwan SM, Turner D, Khalid A. Early intervention to remove mesiodens and avoid orthodontic therapy. Gen Dent 2000;48:166-169. 
19. Primosch RE. Anterior supernumerary teeth--assessment and surgical intervention in children. Pediatr Dent 1981;3:204-215

20. Dinkar AD, Dawasaz AA, Shenoy S. Dentigerous cyst associated with multiple mesiodens: a case report. J Indian Soc Pedod Prev Dent 2007;25:56-59. 